\title{
El teatro en los festejos anarquistas del primero de mayo: entre la conmemoración y el ocio recreativo (Mar del Plata, 1939-1947)
}

\author{
The theater in the anarchist festivities of may 1st: between commemoration \\ and recreational leisure (Mar del Plata, 1939-1947)
}

Milagros Dolabani*

\begin{abstract}
Resumen: El presente artículo busca analizar la conmemoración del día del trabajador en el seno del grupo de teatro "Amigos del Arte", ligado al accionar anarquista de la ciudad de Mar del Plata, Argentina, en los años 1939-1947. En el análisis del evento, realizado en un contexto de ocio recreativo, con elementos festivos y en el que destacan sus componentes rituales, consideraremos algunas investigaciones más clásicas sobre la presencia del anarquismo en Argentina, particularmente las centradas en el estudio de la efeméride para el movimiento, y en el análisis del denominado "teatro anarquista".
\end{abstract}

Palabras clave: teatro, anarquismo, primero de mayo, Argentina

\begin{abstract}
This article aims to analyze the commemoration of may 1st in the theater group "Amigos del Arte", linked to the anarchist action of the city of Mar del Plata, Argentina, in the years 1939-1947. In the analysis of the event, conducted in a context of recreational leisure, with festive elements and whose ritual components stand out, we will consider some classic studies on the presence of anarchism in Argentina, in particular those focused on the study of the event for the movement, and in the in the analysis of the so-called "anarchist theater".
\end{abstract}

Key words: Theater- anarchism- may 1st - Argentina

Recibido: $21 / 03 / 2017$

Aceptado: 21/06/2017

* Argentina. Licenciada en Sociología, Universidad Nacional de Mar del Plata, Grupo Movimientos sociales y políticos en la Argentina Moderna (GMSSPAM), Centro de Estudios Históricos (CeHis), Facultad de Humanidades, Universidad Nacional de Mar del Plata. Concejo Interuniversitario Nacional (CIN). milagrosdola@hotmail.com 


\section{Introducción}

El primero de Mayo ha sido una fecha que históricamente aglutinó al movimiento obrero mundial desde su proclamación como día del trabajador, en la II Internacional de 1889. En Argentina la primera movilización efectuada en su conmemoración fue en 1890 en Capital Federal y, a partir de ese entonces “(...) el $1^{\circ}$ de mayo ha tenido en Buenos Aires una función cambiante para los propios trabajadores; pero también los ha tenido para los sectores dominantes, que lentamente fueron intentando 'cooptar' la celebración obrera en un claro ejemplo de construcción de un orden hegemónico". 1

A pesar de ser uno de los eventos más convocantes para el movimiento obrero, y como sostiene la cita expuesta arriba, los distintos sectores que lo componían pugnaron por adjudicarle sus propios significados, apropiándose de la fecha de modo diferencial desde esa primera manifestación a fines del siglo XIX, hasta una vez entrado el siglo XX. Un enfrentamiento clásico en torno a ese día se estableció primero a partir de la oposición que los anarquistas ponían de manifiesto frente a la concepción festiva que el socialismo y el comunismo tenían de una fecha que los ácratas consideraban marcada por la lucha obrera. ${ }^{2}$ Por último, y una vez aparecido el peronismo dentro de la arena política y sindical, distintos sectores cuestionaron fuertemente los significados y valores que adquiriría la fecha con posteridad a 1944, cuando la Confederación General del Trabajo (CGT) tome el rol de organizador del evento y el estado se imponga como institucionalizador de la fecha, desplegando sus símbolos patrios y remarcando la pacificación lograda en la "fiesta del trabajo" peronista. ${ }^{3}$

En este marco el anarquismo fue un movimiento que participó activamente en su conmemoración, poniendo a disposición de la efeméride los elementos y herramientas que utilizaba como modus operandi: la huelga, la movilización y las concentraciones callejeras, junto al desarrollo de actos varios, muchas veces con oradores y delegados designados para la ocasión, daban forma a un evento que en principio buscaba conmemorar a los mártires de Chicago, así como también efectuar reclamos por la jornada laboral de ocho horas. No obstante, la importancia vertida sobre la fecha no se agotaba en la "auto representación callejera de una clase social", mediante la realización de desfiles y manifestaciones en la vía pública, sino que constituía un evento propicio para movilizar los múltiples dispositivos que el anarquismo contaba para la "difusión de las ideas". De esta manera la oratoria, las conferencias, la música y el teatro, reunidos bajo la forma de velada artística o cultural, congregaban en un mismo evento al activismo libertario y a los distintos sectores que se proponía atraer, desarrollándose por lo general dentro de los espacios de reunión de los núcleos anarquistas, como los ateneos, bibliotecas, círculos, y en ocasiones salas de teatro propias o rentadas para la ocasión.

\footnotetext{
${ }^{1}$ Aníbal Viguera, "El primero de Mayo en Buenos Aires, 1890-1950: evolución y usos de una tradición”, Boletín del Instituto de historia argentina y americana Dr. Emilio Ravignani, $\mathrm{n}^{\circ}$ 3, 3ra serie, 1er semestre de 1991, pp. 53-79, p. 54.

2 Juan Suriano, "Banderas, héroes y fiestas proletarias. Ritualidad y simbología anarquista a comienzos de siglo", Boletín del Instituto de historia argentina y americana Dr. Emilio Ravignani, n 15, 3ra serie, 1er semestre de 1997, pp. 71-99.

${ }^{3}$ Viguera, Ibid.
} 
Dentro del universo de militancia y sociabilidad ácratas, el teatro fue una de las actividades artísticas más promovidas mediante la conformación de "cuadros filodramáticos" pertenecientes a sus distintas asociaciones y centros, también reunidos bajo la forma de las veladas teatrales, eventos que "no solo son, desde 1880, el núcleo de las actividades libertarias, sino que también se transforman en el principal vehículo de difusión de esta ideología, pues representan un canal directo de comunicación con el pueblo". 4

Por otro lado, el estudio de la relevancia que el movimiento le otorgó a la fecha, necesariamente lo vincula con distintos intercambios académicos desarrollados en torno al periodo de vigencia del anarquismo en Argentina, pues las formas que adquiría su conmemoración también irán transformándose con el correr de las décadas en que el movimiento tuvo presencia. A ese respecto, aunque la importancia del mismo durante las últimas décadas del siglo XIX y las primeras del XX es innegable, algunos trabajos sostienen que desde entonces su influencia se fue esfumando por distintas causas, entre ellas la pérdida de gravitación de la Federación Obrera Regional Argentina (FORA) en el terreno gremial, la aparición de otras expresiones políticas dentro de las izquierdas con las que se disputaban la influencia por los mismos sectores sociales, el golpe de Estado de 1930 que persiguió, encarceló y deportó militantes, y más tarde, la irrupción del peronismo en la vida política y sindical argentina de los ' 40.

Lo mencionado adquiere sentido considerando que nuestro trabajo se centra en el grupo filodramático Amigos del Arte, cuyo periodo de actividad comprende los años de 1939 a 1947, dentro de un espacio históricamente ligado al activismo libertario de la ciudad de Mar del Plata, la Biblioteca Popular Juventud Moderna (BPJM). Circunscribiéndonos al periodo en que el grupo teatral desarrolló sus actividades, su análisis nos introduce necesariamente en los debates forjados a raíz del contexto espacio temporal en que el movimiento tuvo presencia en nuestro país, pues estudios centrales en el área han ceñido sus explicaciones a lo sucedido en la ciudad de Buenos Aires y a periodizaciones oscilantes entre las décadas de 1890 y 1930, definiendo como "anarquismo argentino" a las conclusiones obtenidas a partir de esos registros.

En nuestro caso nos concentraremos en las formas que la conmemoración del día de los trabajadores adquiría para la agrupación artística dentro de su periodo de actividad, iniciado en 1939 -cuando se efectúa su primera función teatral- y con 1947 como su cierre, momento en que las actividades de la Biblioteca y la Casa del Pueblo son clausuradas por el reciente gobierno peronista. Aunque para su desarrollo no hemos diseñado un marco teórico rígido, nos inspiramos en estudios clásicos dentro de la historiografía marxista que han puesto el eje en el estudio de las prácticas culturales para el análisis de la clase obrera. ${ }^{5}$ De esta manera y oponiéndose a las líneas ortodoxas imperantes en el materialismo histórico, aquellos hicieron hincapié en las tradiciones, sistemas de valores, ideas y formas

\footnotetext{
${ }^{4}$ María Fernanda De La Rosa, “AArte o Propaganda? El teatro anarquista, 1910-1930”, Actas académicas de las XIV Jornadas Interescuelas, 2013, disponible en http://cdsa.aacademica.org/000-010/661

${ }^{5}$ Edward Palmer Thompson, La formación de la clase obrera en Inglaterra, Madrid, Capitán Swing, 2012.
} 
institucionales, elementos constitutivos de una identidad social en común. ${ }^{6}$ Siguiendo con esa línea, optamos por un enfoque "a ras del suelo", que intente concentrarse en las particularidades del objeto de estudio, ayudándonos a comprender mejor el entramado de las lógicas sociales donde se encuentra inmerso. Consideramos que la importancia del enfoque microanalítico adoptado así, estriba en que "resiste mejor (...) la tentación de una reificación de las acciones y de las relaciones, así como de las categorías que nos permiten pensarlas". ${ }^{7}$ Para ello nos hemos servido de una serie de registros que pueden identificarse como personales (autobiografías editadas por miembros del grupo filodramático), fuentes primarias (en particular los libros de actas de las reuniones y asambleas celebradas en la BPJM) y fuentes secundarias, constituidas principalmente por el relevamiento de dos periódicos locales dentro del periodo de interés (El Trabajo, editado por el partido socialista; y el órgano de difusión de la Unión Obrera Local).

Para el análisis de las fuentes seleccionadas, hemos seguido con un enfoque teatral que priorice la relevancia del contexto en el cual toma lugar, pues desde una mirada sociológica entendemos al teatro como un hecho social categorizado no solo por su origen, sino también por las particularidades de la cultura que lo materializa. ${ }^{8}$ De este modo, otorgaremos relevancia al contexto en el que Amigos del Arte se encontraba inmerso, una coyuntura compleja atravesada por importantes transformaciones políticas, económicas y culturales, intentando con ello escapar a los "enfoques inmanentistas" anclados únicamente en el análisis de la dimensión interna teatral. ${ }^{9}$

A partir del enfoque adoptado y de la sistematización y análisis de las fuentes, rastrearemos la caracterización que nuestro grupo efectuaba de la efeméride, considerando algunos estudios centrados en la Buenos Aires de principios del siglo XX, los que destacan como sentido principal la instrumentalización de la fecha en el marco de las luchas sociales y laborales dadas en ese contexto. Adelantándonos al desarrollo de nuestro análisis, no obstante, y a propósito del corrimiento realizado de ese eje espacio-temporal, nuestros registros arrojaron una concepción más festiva de la fecha, la que incluía la realización de veladas teatrales con repertorios cuyas obras se alejaban de los cánones estrictamente ácratas, constituyendo un espacio de esparcimiento y ocio recreativo para sus asistentes.

\footnotetext{
${ }^{6}$ Danilo Albarracín, “Thompson y la formación de la clase obrera: ¿una construcción cultural?”, Revista Materiales de Trabajo, 2012, disponible en www.economiacritica.net

${ }^{7}$ Jacques Revel, Juegos de escala. Experiencias de microanálisis, Buenos Aires, UNSAM edita, 2015, p. 16.

${ }^{8}$ Natalia Di Sarli, Gustavo Rádice y Mariana Quintero, "La problemática del teatro como objeto de estudio", Cuestión, revista especializada en periodismo y comunicación, Vol 1, Número 11, 2006, pp. 1-6.

9 Lorena Verzero, "Hacia una historia material de las prácticas teatrales anarquistas", En las tablas libertarias. Experiencias de teatro anarquista en la Argentina del siglo XX, Lorena Verzero (edición y compilación) sobre textos de Carlos Fos, Buenos Aires, Atuel, 2010.
} 


\section{Estudios sobre anarquismo en la Argentina: un balance desde La Biblioteca Popular Juventud Moderna y el grupo filodramático Amigos del Arte en los años cuarenta}

El periodo temporal y espacial al que se circunscribe este trabajo, necesariamente lo vincula con investigaciones que han propuesto ampliar las perspectivas sobre el anarquismo en Argentina, pues algunos de los estudios más resonantes en la materia se han centrado en los registros de la ciudad de Buenos Aires y en temporalidades cercanas al Centenario de la República, postulando a ese momento histórico y a las dos décadas subsiguientes como el umbral que el movimiento no pudo traspasar. Trabajos como los de Juan Suriano o bien Dora Barrancos, han propuesto a los años que recorren desde finales del siglo XIX hasta las décadas de 1910, 1920 y 1930 como el periodo en el que la actividad del movimiento anarquista tuvo su auge y caída, así como también han puesto el eje de sus investigaciones en los acontecimientos ocurridos en la ciudad de Buenos Aires. Suriano en particular, ha analizado cómo la importante presencia del anarquismo no pudo sortear las transformaciones sociales, políticas y culturales gestadas a principios del siglo XX, marcando como hito de su declive la sanción de la ley electoral de 1912, ley que ampliaba la participación política ciudadana estableciendo el sufragio universal, secreto y obligatorio. ${ }^{10}$ Asimismo el notable crecimiento y la diversificación de las industrias culturales explican en parte el detrimento de la influencia de las alternativas culturales difundidas desde el movimiento, ${ }^{11}$ sumado a la aparición de otras expresiones políticas y gremiales como por ejemplo el sindicalismo, que disputó con aquel la influencia en el movimiento obrero. ${ }^{12}$

Por su parte, Barrancos ha expuesto en una línea similar, que a partir de la década del '20 el Estado conducido por el partido Unión Cívica Radical (UCR) irá ocupando cultural y educativamente los espacios antes autónomos en manos de las vanguardias, es decir por el socialismo y el anarquismo. En ese sentido el arsenal de dispositivos educativos y culturales que los libertarios desplegaron para conformar una cultura de oposición y contrarrestar los efectos integradores perseguidos por el sistema políticojurídico, resultaron desproporcionales a medida que progresaba el periodo, provocando su declive. $^{13}$

No obstante lo expuesto por los autores mencionados, una serie de investigaciones han intentado objetar la periodización aludida, puntualmente al Centenario de la República

\footnotetext{
10 Juan Suriano, "La reforma electoral de 1912 y la impugnación anarquista”, Estudios sociales número 43, segundo semestre de 2012, pp. 91-104.

${ }^{11}$ Juan Suriano, "Las prácticas culturales del anarquismo argentino", Encuentro cultura y práctica del anarquismo, desde sus orígenes hasta la primera guerra mundial, Cátedra México-España de El Colegio de México, Marzo de 2011. Disponible 2011http://federacionlibertaria.org/BAEL/Archivo/Tesis,\%20monografias/Suriano\%20=\%20Pr\%C3\%A1cticas\%20cultur ales\%20-\%20Argentina.pdf

12 Juan Suriano, 2012, op. cit.

${ }^{13}$ Dora Barrancos, Anarquismo, educación y costumbres en la Argentina de principios de siglo, Buenos Aires, editorial contrapunto, 1990.
} 
como el punto de inflexión en el accionar del movimiento. Migueláñez Martínez ha señalado a esa fecha, 1910, como "una fractura en los estudios del anarquismo argentino"14 explicada en parte por la centralidad que ha tenido el peronismo dentro de los estudios históricos en el país, por los criterios de "éxito o fracaso" que la historiografía argentina ha utilizado para efectuar sus investigaciones, así como por la agenda seguida por la historiografía marxista -vía Eric Hobsbawm- que vio al movimiento libertario como parte de vestigios salvajes de tradiciones arcaicas. Agustín Nieto ha sostenido a ese respecto que la conformación de cierto "sentido común historiográfico"15 contribuyó a obnubilar el desarrollo de investigaciones más allá de lo acontecido en la ciudad de Buenos Aires, cuyos registros y resultados fueron extrapolados hacia el resto del país, ignorando experiencias que trascendieran esos límites geográficos. Asimismo, esa caracterización sobre el "anarquismo argentino" encorsetó a las investigaciones posteriores dentro del rango de años señalados, identificándolos como el límite que el anarquismo no pudo trasvasar, ajustándolas al accionar de la Federación Obrera Regional Argentina (FORA) y a los registros del periódico La Protesta. Por último el autor coincide con Migueláñez Martínez al señalar que el análisis histórico hegemónico estableció una relación cuasi mecánica entre "artesano-oficio-anarquismo (como ideología pre-moderna); a la cual se le contrapone esta otra línea de análisis: obrero de la gran industria-sindicatos únicos por rama-comunismo (como ideología moderna)."16

En esa línea de análisis, trabajos como los de Osvaldo Graciano ${ }^{17}$, María Bordagaray $^{18}$ y nuevamente, Agustín Nieto ${ }^{19}$, muestran también que la presencia del movimiento persistió a pesar de la caída de la influencia de la FORA tras el golpe de estado de 1930. Así las iniciativas editoriales y la escritura sobre la realidad argentina y mundial; el enrolamiento de las mujeres, los universitarios y la juventud además de los obreros, como corolario de la fundación de la Federación Anarco Comunista Argentina (FACA) en 1935, constituyeron intentos de renovación en sus actividades y tácticas respecto a la movilización política y sindical en el mundo obrero de las décadas del '30 y '40. López Trujillo constituye otro ejemplo de las investigaciones centradas en ese lapso temporal, al indagar sobre la presencia del movimiento durante la denominada "década infame" -entre 1930 y 1943- en particular, sus intentos de organización mediante el análisis

\footnotetext{
${ }_{14}$ María Migueláñez Martínez, “1910 y el declive del anarquismo argentino. ¿Hito histórico o hito historiográfico?”, Rey Tristán, Eduardo; Calvo González, Patricia, XIV Encuentro de Latinoamericanistas Españoles: congreso internacional, Sep. 2010, Santiago de Compostela, España. Universidad de Santiago de Compostela, Centro Interdisciplinario de Estudios Americanistas Gumersindo Busto; Consejo Español de Estudios Iberoamericanos, pp. 436-452, 2010, Cursos e Congresos; 196, p. 447.

15 Agustín Nieto, "Notas críticas en torno al sentido común historiográfico sobre 'el anarquismo argentino"”, A contra corriente, Vol. 7, No.3, Spring 2010, pp. 219-248.

${ }^{16}$ Idem, p. 230.

${ }^{17}$ Osvaldo Graciano, "La escritura de la realidad. Un análisis de la tarea editorial y del trabajo intelectual del Anarquismo argentino entre los años '30 y el Peronismo", Revista Izquierdas, n 12, abril 2012, pp. 72-110.

18 María Eugenia Bordagaray, "Controversias libertarias: La interpelación anarquista en tiempos del peronismo" [en línea], Tesis de posgrado, Universidad Nacional de La Plata, Facultad de Humanidades y Ciencias de la Educación, en Memoria Académica, disponible en: http://www.memoria.fahce.unlp.edu.ar/tesis/te.1066/te.1066.pdf.2014

${ }^{19}$ Agustín Nieto, "Conflictividad obrera en el puerto de Mar del Plata: del anarquismo al peronismo. El Sindicato Obrero de la Industria del Pescado, 1942-1948”, Revista de Estudios Marítimos y Sociales, n ${ }^{\circ}$, Mar del Plata, 2008 , pp. 35- 44.
} 
de la constitución del Comité Regional de Relaciones Anarquistas (CRRA) en 1932, y su accionar posterior, con la organización de la FACA. ${ }^{20}$

Teniendo presente lo expuesto en dichas investigaciones, la relevancia de la tradición anarquista en Mar del Plata constituye a la ciudad como una experiencia significativa para el análisis. La BPJM constituyó desde su fundación en 1911, un punto de encuentro para el activismo obrero de la ciudad, siendo sede de La Casa del Pueblo, espacio donde se reunían los gremios autónomos; contando además con el despliegue de múltiples actividades que superaban sus fines gremiales y políticos, como por ejemplo disputar el tiempo libre de los trabajadores y trabajadoras. ${ }^{21}$ Para ello desarrollaron actividades de promoción cultural y de esparcimiento que abarcaban la organización de conferencias o la realización de pic-nics, formas habituales dentro de la tradición de promoción cultural anarquista en argentina durante fines del siglo XIX y la primera mitad del siglo $\mathrm{XX} .^{22}$

Como parte de esos propósitos se conforma en 1939 el conjunto filodramático Amigos del Arte, a raíz de una función que un grupo de jóvenes militantes realiza en una sala de teatro local, los que recién se incorporaban a las actividades de la BPJM. Su periodo de actividad recorre ocho años ininterrumpidos hasta 1947, en los que se pondrán en escena más de 27 obras de teatro a lo largo de 37 funciones teatrales, siempre de modo honorario. En todo su periodo de actividad, la conmemoración del día del trabajador es una constante, no sólo en actos y concentraciones realizados en las calles céntricas de la ciudad, sino también mediante la realización de veladas artísticas en la noche previa a esos eventos callejeros.

En sintonía con las investigaciones aludidas, la presencia del movimiento en Mar del Plata se extendió con distinta intensidad a lo largo de las décadas mencionadas, constituyendo los años '40 un período con gran representación dentro de las luchas gremiales experimentadas en la ciudad. No obstante, antes de adentrarnos en ese aspecto, es necesario mencionar algunas de las características destacadas de Mar del Plata, para comprender mejor la presencia que allí desarrolló el movimiento.

En primer término, señalamos que la ciudad está ubicada geográficamente a 400 $\mathrm{km}$ de la ciudad de Buenos Aires sobre la costa atlántica argentina, y fue fundada por miembros de la oligarquía terrateniente hacia finales del siglo XIX. A pesar de ligarse en principio a las actividades propias del modelo agrícola ganadero, rápidamente se constituyó en una lujosa villa balnearia donde acudía la élite nacional durante la temporada estival, especialmente la acaudalada oligarquía terrateniente. Por más de tres décadas la "Biarritz argentina" fue el escenario donde los personajes más destacados de la política,

\footnotetext{
${ }^{20}$ Fernando López Trujillo, Vidas en rojo y negro. Una historia del anarquismo en la "década infame”, Buenos Aires, Letra libre, 2005.

${ }^{21}$ Actas Biblioteca Juventud Moderna, Reunión comisión administrativa 02/08/1946, libro II, página 1.

${ }^{22}$ Nicolás Quiroga, "Prácticas políticas y cambio cultural: anarquistas autodidactas hacia mediados de 1940", Estudios Ibero-americanos, $\mathrm{n}^{\circ}$ 1, vol. XXX, junio de 2004, pp. 139-160.
} 
cultura y la economía desfilaron por sus playas, hoteles y confiterías, ${ }^{23}$ imprimiendo a la ciudad un ritmo de vida signado por el comienzo y el final de la temporada de verano.

Sin embargo, ese escenario de reunión de la opulencia criolla quedará vacío con el crack del '29 y la recesión del comercio internacional, frenando la entrada de divisas provenientes de la venta de productos primarios, y estimulando un proceso conocido como industrialización por sustitución de importaciones (ISI). Ese viraje del modelo económico nacional posibilitó el desarrollo de una incipiente industria nacional, y con ella, el surgimiento de nuevas capas dentro de las clases medias y altas, las que lentamente irían ocupando el lugar de veraneantes que la elite había dejado vacante. De este modo aquel balneario aristócrata va convirtiéndose paulatinamente en balneario de masas, estimulado asimismo por la sanción de una serie de medidas legales tendientes a posicionar a la ciudad como el balneario argentino por excelencia. ${ }^{24}$ La composición social de los veraneantes así se verá trastocada, proviniendo ahora de las capas medias, altas y de algunos sectores populares, los que engrosan los contingentes que llegan a la ciudad en verano: “(...) de unos 65000 turistas arribados en 1930 se pasa a unos 320000 al término del decenio, llegando a 500 mil en 1946 y un millón en 1950". ${ }^{25}$

Las transformaciones aludidas también se expresaron en el juego político nacional, pues a la crisis económica mencionada se le añade una crisis política-institucional representada por el golpe de estado de 1930 en manos del general José F. Uriburu, quien destituye al presidente democrático Hipólito Yrigoyen. Se abre así un período signado por la persecución política y gremial, y por el cercenamiento de libertades individuales; por mencionar algunos ejemplos ligados al movimiento libertario, éste sufrió la persecución de dos de sus periódicos más reconocidos: La antorcha, y el "decano anarquista" La protesta, deben editarse clandestinamente, sumado a la encarcelación, tortura, fusilamientos y a la deportación de algunos de sus militantes extranjeros más reconocidos. ${ }^{26}$

En Mar del Plata por su parte, la dirigencia política que históricamente había estado a cargo del régimen de comisionados municipales -sistema que designaba a distintos interventores por parte del gobierno Nacional o de la provincia de Buenos Aires, excluyendo la posibilidad del mandato popular mediante elecciones libres- y que se alternaba en el poder con gobiernos escogidos mediante el fraude electoral, comienza en los años '20 un período con preeminencia del Partido Socialista en la Intendencia Municipal. No obstante, dicho período finalizará en 1929 cuando su Intendente, Teodoro Bronzini, es depuesto por una nueva intervención provincial, la que

\footnotetext{
${ }^{23}$ María Liliana Da Orden y Elisa Pastoriza, "Capítulo quinto. La formación de una ciudad moderna. Grupos sociales y ámbitos culturales", A.A.V.V Mar del Plata. Una historia urbana, Buenos Aires, Fundación Banco de Boston, 1991, pp. 165-206.

${ }^{24}$ Elisa Pastoriza destaca en ese sentido una serie de medidas destinadas a posicionar a la ciudad como "legítimo balneario marítimo de nuestras costas" llevadas adelante por la Intendencia y la provincia de Buenos Aires, como la construcción y mejora de carreteras que la conectaran con Buenos Aires, la construcción del icónico edificio Casino, junto a la demolición de la histórica Rambla en la playa Bristol, lugar de paseo de los acaudalados veraneantes que previamente asistían a la ciudad. Elisa Pastoriza, María Liliana Da Orden y Jorge Jofre, "Capítulo cuatro. La vida política", op. cit., pp. 93-207.

${ }^{25}$ Elisa Pastoriza, Los trabajadores de Mar del Plata en vísperas del peronismo, Buenos Aires, Centro editor de América Latina, 1993, p. 28.

${ }^{26}$ Fernando López Trujillo, op. cit.
} 
(...) se vio reforzada por las autoridades emergentes del golpe militar, que legitimaron y prolongaron estas formas ejecutivas no autónomas. Se sucedieron una lista de designaciones compulsivas hasta que en el año 1932 se retornó al sistema eleccionario de gobierno comunal por intendentes y funcionamiento del consejo deliberante. ${ }^{27}$

A ese respecto, será hacia mediados de la década que la organización política y gremial iniciará un proceso de reactivación y cambio, modificándose sus formaciones gremiales, hasta entonces ancladas en la tradición de gremios por oficios. Dorado et al señalan en ese sentido que hasta la década del '40, la clase obrera marplatense se encontraba aún en estado embrionario, sin existir un régimen de grandes factorías como en otros lugares del país. Lo que predominaba era la fabricación de manufacturas, en establecimientos con instalaciones pequeñas y limitados medios tecnológicos. Dicho período es señalado por los autores como "de transición capitalista con características pretayloristas", pues la formación de una clase obrera de tipo industrial empezaría a mediados de los años '30, con la aparición del sindicato de la industria de la construcción, la Federación Obrera Nacional de la Construcción (FONC), y el sindicato obrero de la industria del pescado (SOIP) en $1943{ }^{28}$ actividades que, junto a los servicios brindados al turismo, atraían mayoritariamente la mano de obra trabajadora. Una de las contrapartes a dicha organización sindical, fue el protagonismo que el estado irá asumiendo en tanto interventor de los conflictos laborales; el flamante Departamento Provincial del Trabajo será ahora quien regule las condiciones laborales y se imponga como interlocutor obligatorio de los conflictos entre el capital y el trabajo. ${ }^{29}$

Por su parte la composición demográfica local en ese entonces se incrementa considerablemente coadyuvada por dos procesos superpuestos: por un lado, un crecimiento vegetativo de su población producto del nacimiento de nuevas generaciones de marplatenses, hijos y nietos de la población inmigrante que en décadas anteriores había llegado desde ultramar; y por el otro del arribo de flujos migratorios provenientes en su mayoría de ciudades aledañas de la provincia de Buenos Aires. En este sentido el viraje en el modelo económico nacional que impuso la crisis del '29, implicó que miles de personas sean desplazadas de los medios rurales en los que trabajaban, migrando hacia distintos centros urbanos. La llegada de hombres y mujeres en busca de nuevas oportunidades laborales así, se manifestará en un aumento de la población económicamente activa, en el porcentaje de la población ocupada, y con ello, en el grado de sindicalización de la población local. De allí que se conformen nuevos sindicatos, se de la refundación o el fortalecimiento de los preexistentes, aglutinándose preferentemente dentro de las dos "centrales" obreras de la ciudad: la mencionada FONC, de filiación comunista, y la Unión Obrera Local (UOL), que reunía a los sindicatos por oficios autónomos.

\footnotetext{
${ }^{27}$ Elisa Pastoriza, María Liliana Da Orden y Jorge Jofre, op cit., p. 148.

${ }^{28}$ Gustavo Dorado, Lucas González y Oscar Spadari, Entre Bibliotecas y Andamios. Orígenes del movimiento obrero en Mar del Plata 1890-1930, Mar del Plata, Ediciones Suárez, 2013.

${ }^{29}$ Nieto, 2013, op. cit.
} 
Un párrafo aparte merece dicha central, pues la UOL estuvo estrechamente vinculada al objeto del presente trabajo, es decir, al movimiento anarquista y al sindicalismo con sede en la BPJM. Su antecedente inmediato había sido la Federación Obrera Local (FOL) la que, alineada en las décadas previas con la FORA, rompe sus relaciones a partir de 1941, y se asocia con el accionar de la FACA. Como coralario de dicha reconfiguración, se realizan modificaciones en algunas de las lecturas efectuadas hasta el momento, criticando la negativa a adquirir conquistas laborales por estar sancionadas legalmente, así como también caracterizando a las otras centrales obreras nacionales, la Confederación General del Trabajo (CGT) y la Unión Sindical Argentina (USA) como burocráticas, y la FORA como sectaria. ${ }^{30}$ Una vez constituida como tal, la UOL tuvo una participación activa dentro de los distintos conflictos locales, asistiéndose a un proceso de movilización ascendente hacia mediados y fines de la los años '40, con un auge entre 1946 y 1947 cuando se agudiza el nivel de conflictividad social. Dicho proceso, no obstante, quedará trunco por el avance el partido laborista en el ámbito político, el activismo de la CGT en el gremialismo local mediante la conducción de sindicatos existentes y la fundación de $\operatorname{otros}^{31}$ y la negativa de la FONC a constituir una central obrera unificada, factores que fueron debilitando la influencia de la UOL en el mundo obrero de la ciudad. Pero fundamentalmente la persecución y clausura a finales de 1947 de la Casa del Pueblo y de la BPJM por el reciente gobierno peronista, fue un punto de ruptura para las actividades que allí se desarrollaban, incluyendo la realización de conferencias, las asambleas gremiales, y la realización de actividades culturales y artísticas por parte del conjunto filodramático Amigos del Arte.

\section{Ocio recreativo, festividad y ritual político de identidad anarquista: las veladas artísticas del primero de Mayo}

El periodo de importantes cambios abierto con la década de 1930, se expresó también en el ámbito de la cultura, asistiéndose a una expansión y superposición de los soportes de comunicación; la presencia de la radiodifusión, vigente desde las décadas previas, se consolida y se produce un auge en la industria cinematográfica. Ambos soportes irán influyendo y desplazando lentamente a las artes escénicas de las carteleras nacionales y locales, especialmente al teatro y la música, dado el gran impulso que la industria cinematográfica irá adquiriendo, especialmente a partir de la fundación de las compañías nacionales Argentina Sono Film y Lumiton en $1933 .{ }^{32}$ La rápida expansión del cine en ese sentido implicó que la composición del teatro se vea trastocada, pues significó para los artistas y técnicos el traspaso entre uno y otro soporte, transferencia que también incluyó al radioteatro, género ya instalado y del que muchos artistas provenían.

\footnotetext{
${ }^{30}$ Idem.

31 Agustín Nieto, “Asociacionismo obrero y popular en la aldea, Mar del Plata (1940-1960)”, Omar Acha y Nicolás Quiroga (eds.) Asociaciones y política en la Argentina del siglo XX. Entre prácticas y expectativas, Buenos Aires, Prometeo, 2015, pp. 179-200.

${ }^{32}$ Carolina González Velazco, "Mercado de entretenimientos y cultura urbana durante los años de la entreguerra", Revista Forjando, número 6, año 2014, pp. 64-75.
} 
Esas transformaciones, junto al aumento de la escolarización y a los descensos en las tasa de analfabetismo, trazan un cuadro que complejizaba la composición de las audiencias culturales asistentes a la Biblioteca, ${ }^{33}$ cuyo tiempo libre se verá cada vez más atravesado por la pujante industria del entretenimiento. En ese marco el grupo filodramático era una de las actividades que, junto a la realización de conferencias de carácter científico o al desarrollo de eventos como pic-nics al aire libre, pretendía disputar el tiempo libre de las y los trabajadores, para lo cual tenía a su cargo

(...) la faz recreativa, la cual debía desarrollarse en un sentido cultural de manera que coadyuvara a la acción emancipadora que llevaba a cabo la Biblioteca. Era ya un concepto unánimemente aceptado que el teatro es un medio altamente eficaz para divulgar doctrinas y enseñanzas de superación (...) Por otra parte, esa labor teatral (...) importaba una ayuda económica muy valiosa para la tarea cultural y sindical de la casa. ${ }^{34}$

Colaborar con los gremios reunidos en la UOL, con el periódico de esa central obrera, con la Biblioteca, o bien con distintas instituciones locales o de ciudades cercanas a Mar del Plata, eran las formas habituales que revestían sus eventos culturales, a lo largo de sus ocho años de actividad ininterrumpida. No obstante, y más allá del carácter benéfico de esas funciones, las fechas para sus puestas en escena no siempre eran escogidas de acuerdo a las necesidades de las causas e instituciones con las que se proponía colaborar, destacándose en ese aspecto la realización de las veladas desarrolladas para la conmemoración del primero de mayo.

En efecto, la representación de las obras en el marco de la efeméride constituía una constante a lo largo del periodo analizado, evento que seguía un esquema con componentes rituales que se repetían año a año, adoptando leves variaciones. El $1^{\circ}$ de mayo era también la fecha que daba inicio a las actividades del grupo filodramático, paralizadas a partir del mes de diciembre debido al inicio de la temporada de verano, cuando los miembros del conjunto filodramático se empleaban temporalmente en diversos trabajos no asociados necesariamente con el teatro. El inicio y final de la temporada estival así, marcaba el ritmo de vida de la ciudad, cuya estacionalidad en el mercado de trabajo afectaba el desarrollo de las actividades de Amigos de Arte y de la vida gremial de la Casa del Pueblo, ${ }^{35}$ así como también a otros grupos de teatro vocacional de la ciudad cuya temporada comenzaba igualmente en el otoño. ${ }^{36}$

Retomando el análisis de las veladas artísticas, destacamos que constituían un evento tradicionalmente desarrollado por el movimiento libertario dentro de sus distintas variantes, basado fundamentalmente en

\footnotetext{
${ }^{33}$ Nicolás Quiroga, "Lectura y política. Los lectores de la Biblioteca Popular Juventud Moderna de Mar del Plata (fines de los años treinta y principios de los cuarenta)", Anuario IEHS, número 18, 2003, pp. 449-474.

${ }^{34}$ Héctor Woollands, Recuerdos de un militante anarquista, Mar del Plata, Grupo editor El Martillo, 1999, pp. $37,38$.

35 Quiroga, 2003, op. cit.

36 Gabriel Cabrejas, "Mar del Plata 1940: teatro y periodismo. La aparición de la crítica", Nicolás Fabiani (comp.) Estética e historia del teatro marplatense. Volumen III, Mar del Plata, Editorial Martín, 2004.
} 
(...) un tipo de reunión, generalmente llevada a cabo en algún local propio o alquilado para la ocasión, en la que el público iba a disfrutar de una serie de espectáculos que solían incluir, en la misma jornada, desde una conferencia hasta una obra de teatro. La velada era (...) fundamentalmente un espacio de cruce y mezcla entre arte y política, y entre diversos géneros discursivos (también de la política y el arte) siempre ligados a la representación. ${ }^{37}$

En nuestro caso de estudio y como decíamos previamente, la realización de las veladas artísticas del primero de mayo es una constante dentro del universo de fuentes consultadas, a excepción del año 1941 cuando "se llevará a cabo en el cine Avenida, tarde y noche, dos actos cinematográficos". ${ }^{38}$ Estimamos que en ese momento la carencia de un espacio propio que pudiera utilizarse como teatro, sumado a la incipiente conformación del grupo, llevó a que se optara por la proyección de cintas cinematográficas, en lugar de realizarse una velada teatral. A ese respecto, mencionamos que hacia finales de 1941 se construye el denominado "salón de actos" de la Biblioteca, espacio donde el grupo filodramático podía efectuar sus ensayos y realizar sus funciones, hecho que en adelante le imprimiría un mayor dinamismo y cohesión interna, como veremos más adelante.

Prosiguiendo con el análisis de las fuentes periodísticas consultadas, hallamos que en 1944 tampoco se realizaron las veladas y no se registraron actos ni concentraciones en las calles céntricas de la ciudad, como era habitual para la fecha, pues el gobierno de facto de ese entonces las había vedado.

A excepción de los años mencionados, en el resto de la periodización se asiste a la repetición de características en la conmemoración de la fecha, donde las obras se realizaban dentro de la víspera y se anunciaban en el marco de las concentraciones o mítines realizados en la ciudad. Las veladas se efectuaban el día previo, con el objeto de dejar libre la mañana del $1^{\circ}$ de mayo para realizar los tradicionales actos públicos en las calles céntricas, jornada definida por los miembros de la comisión administrativa de la Biblioteca como una que "tradicionalmente se lleva a cabo" el día 30 de abril. ${ }^{39}$

El contexto de la conmemoración era el mismo, pero se realizaban durante dos jornadas distintas y se anunciaban por separado en los periódicos relevados, dándose un desdoblamiento en su desarrollo y difusión. De esta manera se escindía en un espacio para los actos públicos, con la presencia de oradores pertenecientes a la Unión Obrera Local o de delegados de la ciudad de Buenos Aires, y el otro espacio correspondía a las veladas realizadas durante la noche previa.

Esos eventos, asimismo, servían a los fines de obtener fondos pues se cobraba entrada a \$1 y se especificaba en su difusión la gratuidad del ingreso de menores de 12 años, permitiéndonos inferir su carácter familiar. El horario para las mismas correspondía

\footnotetext{
${ }^{37}$ Ansolabehere, Pablo, Literatura y anarquismo en Argentina (1879-1920), Rosario, Beatriz Viterbo editora, 2011 , p. 61.

${ }^{38}$ El Trabajo: 30/04/1941. En este caso la conmemoración del primero de mayo se unió al reclamo por la liberación de tres obreros anarquistas encarcelados en la localidad bonaerense de Bragado, para lo cual se conformaron distintos comités de ayuda y propaganda.

${ }^{39}$ Actas Biblioteca Juventud Moderna, Reunión comisión administrativa 10/04/1947, libro II, página 30.
} 
entre las 21 y 21.30 horas, realizándose en el contexto de un día feriado, pues en Argentina el $1^{\circ}$ de mayo es decretado como día no laboral desde el año 1925.

En cuanto a la forma que adquirían las representaciones en ese marco, puede trazarse un esquema cuyo programa contaba con una o dos partes y en ocasiones se utilizaba el entreacto para realizar conferencias, o "diálogos en verso". Mientras que en la primera parte se ponían en escena obras con estructuras que variaban entre uno, dos o tres actos, en la segunda solían realizarse recitales con guitarras, formato que solía invertirse y no era exclusivo del día del trabajador. En 1943, por ejemplo, la prensa socialista publicaba un balance de la jornada en la ciudad:

Los gremios adheridos a la Unión Obrera Local realizaron los actos anunciados con gran concurso de trabajadores. La velada realizada en la noche del viernes en el salón de actos de la Casa del Pueblo se vio sumamente concurrida (...) En un entreacto pronuncio una interesante conferencia sobre 'La mujer en las filas obreras', el delegado metropolitano Horacio Badaracco. ${ }^{40}$

Y señalaba luego la participación de la entidad gremial en un mitín realizado durante la mañana del $1^{\circ}$ de mayo en las intersecciones de las avenidas céntricas Luro e Independencia, a pocas cuadras de la Biblioteca y en el cual también usarían la palabra dos delegados de Capital Federal: Badaracco y Cabrera.

Por su parte los recitados de "diálogos en verso" realizados al comienzo de las veladas, eran por lo general entre dos participantes o bien por un integrante acompañado por músicos con guitarras criollas para, en una segunda parte, desarrollar la función de las obras escogidas. Así sucedía en el año 1947 cuando el programa contaba en una primera parte con la "presentación del cantor Ricardo Poli acompañado de sus guitarristas Manughian y Gómez" y con "recitados por parte de un integrante de la agrupación", y luego en la "segunda parte: se pondrá en escena la hermosa comedia dramática en tres actos original de Julio Sánchez Gardel Amor de Otoño" 41

Un elemento relevante para la reconstrucción del contexto en el que se desarrollaban estas veladas y como decíamos previamente, lo constituye el espacio físico en el que se llevaban a cabo. Era habitual para esos fines el uso del salón de actos o "teatro chico" como lo llamaban sus miembros, tal como se convocaba en los periódicos consultados: "Patrocinado por la Unión Obrera Local se llevará a cabo el 30 del corriente mes, en el salón de actos de la Casa del Pueblo, un gran festival teatral con la actuación escénica de la Agrupación Artística Amigos del Arte". ${ }^{42}$

Sin embargo, en el año 1943 el salón de actos es clausurado, pues a pesar de haber sido inaugurado hacía dos años, aún contaba con "un escenario improvisado, el salón sin acústica, sin butacas, sin luces convenientemente distribuidas...", ${ }^{43}$ utilizando caballetes y

${ }^{40}$ El Trabajo: $3 / 05 / 1943$.

${ }^{41}$ Periódico Unión Obrera Local: 30/04/1947.

${ }^{42}$ El Trabajo: 19/04/1947.

${ }^{43}$ El Trabajo: 10/06/1943. 
tablones que oficiaban de escenario, desmontados una vez finalizadas las actividades. ${ }^{44}$ Por este motivo el uso del salón para la realización de las funciones se vio interrumpido hacia agosto de 1943, cuando representantes del comisionado municipal "han prohibido la realización de festivales con el escenario actual", ${ }^{45}$ lo cual estimamos, se relacionaba con que el escenario no estaba capacitado para soportar el peso de varias personas en escena. ${ }^{46}$ Esta situación prohibitoria impuso que la actuación del grupo filodramático se trasladara a las salas de teatro y cines locales debiendo abonar un alquiler por aquellas, como sucedió tanto en 1945 como en 1946, cuando se rentaron las salas locales del cine Belgrano, ${ }^{47}$ y la del Teatro Odeón, ${ }^{48}$ para las veladas del 30 de abril respectivamente.

En cuanto al carácter de las obras puestas en escena es interesante destacar que no siempre referían a temáticas ligadas a la conmemoración de la fecha, utilizando textos y autores no asociados directamente con fines propagandistas, destacándose Hijos del Pueblo del periodista, dramaturgo y militante libertario argentino Rodolfo González Pacheco, ${ }^{49}$ como la única pieza representada que iba en ese sentido. ${ }^{50}$ Este dato resulta relevante pues contrasta con parte de la bibliografía consultada sobre teatro anarquista: dos exponentes en la materia, como Fos ${ }^{51}$ o Golluscio de Montoya, ${ }^{52}$ mencionan como una de las características principales de esta actividad cultural la presencia de elementos propagandísticos o de mensajes proselitistas explícitos, pues "El teatro en el movimiento anarquista tuvo un sistema de producción, recepción y circulación propios que le permitió desarrollarse y ser útil a su función primordial de instrumento de propaganda ideológica." 53 En nuestro caso de estudio, empero, no sólo las obras escogidas para esta fecha referían a temáticas heterogéneas como por ejemplo la vida rural argentina (Los Mirasoles y Amor de Otoño, de Julio Sánchez Gardel, en 1943 y 1947 respectivamente), sino que además eran tomadas de autores que provenían de soportes y géneros del circuito comercial como el radioteatro, el cine, o de géneros comerciales como la revista y el sainete dentro del teatro

\footnotetext{
${ }^{44}$ Actas Biblioteca Juventud Moderna, Reunión comisión administrativa 15/01/1942, libro I, página 181.

45 Actas Biblioteca Juventud Moderna, Reunión comisión administrativa 05/08/1943, libro I, página 241.

${ }^{46}$ Aquí nos referimos a que el uso del salón estaba vetado para las actividades que necesariamente usaran su escenario, pero no observamos lo mismo para el desarrollo de otras actividades abiertas al público como la realización de conferencias. Es así que a pesar de que el grupo filodramático se veía impedido de utilizar aquel espacio, se desarrollaron diferentes "conferencias científicas". Ese fue el caso de la conferencia brindada por el abogado Urbano Eyras sobre "La filosofía y el mundo" (El Trabajo, 21/08/45), o bien la del Doctor Scavuzzo sobre "Los vicios del hombre" (El Trabajo, 10/11/45). Así también el salón era cedido para que otras entidades lo utilizaran con el mismo propósito, tal como sucedía en Junio de 1946 cuando diera sesión la conferencia regional del Partido Socialista, con motivo del "cincuentenario de la constitución del partido" (El Trabajo, 18/06/1946).

${ }^{47}$ El Trabajo: 26/04/1945.

${ }^{48}$ El Trabajo: 28/04/1946.

49 María Fernanda de La Rosa "Detrás de escena. Rodolfo González Pacheco y su influencia en la cultura libertaria argentina, 1910-1930", Terceras Jornadas Nacionales de Historia Social 11, 12 y 13 de mayo de 2011 La Falda, Córdoba, Argentina, disponible en

http://www.cehsegreti.org.ar/historia-social-3/mesas\%20ponencias/MESA\%207/Ponencia_De\%201a\%20Rosa.pdf

${ }^{50}$ El Trabajo: 26/04/1945.

${ }^{51}$ Lorena Verzero (edición y compilación), En las tablas libertarias. Experiencias de teatro anarquista en Argentina a lo largo del siglo XX. Sobre textos de Carlos Fos, Buenos Aires, Atuel, 2010.

52 Eva Golluscio de Montoya, "Elementos para una 'teoría' teatral libertaria (Argentina 1900)", Latin American Theathre review, Fall 1987, pp. 85-93.

${ }^{53}$ Carlos Fos "Los límites espaciales en el teatro libertario. Una aproximación al concepto de espacio", La revista del CCC, Enero-Agosto 2009, n 5-6, en línea: http: //www.centrocultural.coop/revista/articulo/126/, pp. 1.
} 
(La cena de los neurasténicos de Manuel Romero; Ropa Nueva, Ropa Vieja, de Ivo Pelay, ambas en 1945), e incluso se representaron obras con motivos religiosos (Vía Crucis, en 1942).

Teniendo presente esa reflexión, y considerando los elementos descritos en tanto componentes de las veladas artísticas, postulamos que más allá de la importancia vertida sobre la conmemoración del día de los trabajadores, en muchas ocasiones éste suponía un momento de recreación dentro del tiempo libre de quienes concurrían a las funciones y a la BPJM. Estas observaciones coinciden con lo expuesto por Rodolfo Porrini respecto a las actividades culturales de los anarquistas en Montevideo, donde la realización de eventos en el marco de la Federación Obrera Regional Uruguay (FORU), en particular sus veladas, se enlazaban muchas veces con formas de entretenimiento y ocio recreativo dentro del tiempo libre de los trabajadores durante las décadas del 30 y $40 .{ }^{54}$ En nuestro caso, el carácter de su realización en un día feriado, dentro de un horario nocturno que constituía un ámbito familiar, sumado al contenido de los textos utilizados para las representaciones, nos invitan a pensar a las veladas o festivales teatrales en un sentido amplio, trasvasando los fines conmemorativos asociados tradicionalmente con la fecha, así como también a los sentidos atribuidos al teatro anarquista en las investigaciones aludidas.

Así, y en relación al primer aspecto mencionado, cabe destacar que los sentidos adjudicados al "anarquismo argentino" sobre la conmemoración de ese día, destacan los intentos del movimiento por imprimirle su propio sello durante fines del siglo XIX hasta la primera mitad del XX, particularmente su diferenciación del socialismo y el comunismo en tanto festividad. Así, según investigaciones centradas en los registros de principios del siglo pasado, el $1^{\circ}$ de mayo constituía una jornada para la lucha y la conmemoración de sus mártires y no una fiesta a la que acudir en el día feriado, ${ }^{55}$ siendo también una ocasión para realizar reclamos generales de la actualidad política nacional e internacional, especialmente a partir de mediados de los años ' $30 .^{56}$

No obstante, en nuestro trabajo junto al carácter recreativo dentro del tiempo libre de las veladas que mencionamos, también advertimos características que, sumadas a las concentraciones y mítines realizados en la mañana siguiente, contribuían a constituir formas rituales para sus asistentes y organizadores. A ese respecto, retomamos un estudio clásico sobre los rituales de la clase obrera realizado por Hobsbawm, donde define al primero de mayo como el ritual obrero "más ambicioso". 57 El rasgo distintivo del mismo era el de autopresentación de una clase social dentro del espacio público, en tanto conquista simbólica, donde la reivindicación original de la fecha -la conquista laboral por ocho horas o bien la conmemoración de los Mártires de Chicago- quedó rápidamente en un segundo plano, pues lo que terminó por imponerse fue la afirmación anual de la presencia de una clase social. Por su parte, tanto Porrini ${ }^{58}$ como Nieto $^{59}$ destacan la importancia de

\footnotetext{
${ }^{54}$ Rodolfo Porrini, “Anarquistas en Montevideo: ideas y prácticas en torno al 'tiempo libre' de los trabajadores (19301950)", História: debates e tendencias, Vol. 13, número 2. jul. /dez., 2013, pp. 357-371.

${ }^{55}$ Suriano, 1997, op. cit.

${ }^{56}$ Aníbal Viguera, op. cit.

57 Eric Hobsbawm, "La transformación de los rituales obreros", El mundo del trabajo. Estudios históricos sobre la formación y evolución de la clase obrera, Barcelona, Crítica, 1987.

${ }^{58}$ Rodolfo Porrini, op. cit.
} 
las veladas y actos realizados por distintos grupos anarquistas en Sudamérica como componentes de la configuración identitaria de quienes asistían y como factor religante del colectivo, pues implicaban la formación o reforzamiento de lazos de solidaridad y "sana camaradería", aspecto también subrayado por Hobsbawm.

En nuestro caso la reiteración de algunos de sus elementos constitutivos a lo largo de los años relevados, nos inclina a pensar a las veladas en el sentido aludido. En efecto, las mismas se realizaban siempre un 30 de abril, se respetaba una misma estructura interna con leves variaciones en su orden (recitados-obra-conferencia-recital de guitarras criollas) y se celebraban en un mismo espacio, el salón de actos de la Biblioteca. Cabe mencionar que cuando aquel no estuvo habilitado, se acudió al alquiler de salas de cine o teatros, revelando la importancia otorgada al evento. Finalmente, mencionamos que a pesar de que el anarquismo tradicionalmente cuestionó la caracterización de ese día como festividad, la realización de las veladas no estaba exenta de componentes festivos, tal como se anunciaba en uno de los periódicos consultados "[la velada] finalizará con un fin de fiesta a cargo de la agrupación"; 60 revelando así otra de las aristas en su apropiación particular de la fecha.

\section{Consideraciones finales}

De cara al análisis que hemos realizado hasta aquí, en primer término, destacamos a las veladas artísticas del primero de mayo como componentes de un ritual político realizado por los anarquistas, en tanto y en cuanto funcionaban como generadoras de cohesión interna, reforzando sus vínculos de camaradería, y de legitimidad política. Constituían un ritual que operaba tanto internamente en el sentido destacado arriba, como externamente, pues también comprendían los fines de acercarse a nuevos militantes, así como de adquirir visibilidad en el contexto de activismo local. Por su parte también analizamos a las veladas artísticas con sus elementos recreativos y en algunos casos festivos, lo que nos indujo a pensarlas como espacios de encuentro y sociabilidad, más allá de la relevancia adjudicada a la efeméride, como un espacio de recreación dentro del tiempo libre de sus asistentes. En este punto es que retomamos algunos estudios anclados en la experiencia del primero de mayo en Buenos Aires, donde se imponía su carácter conmemorativo, así como las reivindicaciones asociadas a mejoras laborales o a la coyuntura política nacional o internacional. No obstante, observamos como al considerar otras temporalidades y geografías, la festividad y el ocio recreativo emergían como componentes lícitos dentro de sus veladas, los que no implicaban que la dimensión política del evento se viera diluida, sino que más bien, la constituían. Así es que destacamos cómo las formas adquiridas en ese marco contribuían a crear una identidad en común, identidad política anclada en su propia tradición, pero interceptada por la incorporación de nuevos componentes y dimensiones, propios del contexto investigado.

De esta manera, los elementos descritos nos inducen a situar el análisis de la actividad del conjunto filodramático en el sentido que De la Rosa le otorga al teatro libertario, es decir, ubicándolo en el cruce entre ocio, arte, propaganda, política y

${ }^{59}$ Agustín Nieto, 2016, op. cit.

${ }^{60}$ El Trabajo: 29/04/1946. 
educación. ${ }^{61}$ En efecto, coincidimos con la autora en que el esparcimiento y la diversión presentes en las funciones realizadas por los libertarios, no suponían un declive de los fines políticos perseguidos, sino que más bien los conformaban. Así es que la incorporación de elementos alejados de la tradicional difusión del ideal -aspecto central en investigaciones clásicas sobre teatro libertario- nos habla de transformaciones que competían a la concepción del teatro que tenía el conjunto filodramático, pero también del atravesamiento en sus miembros de las transformaciones que en esferas más generales se estaban expresando, especialmente a partir de la década del '30. Mencionamos en ese sentido lo que en el ámbito gremial se suscitaba, en el que por cierto muchos de los miembros del grupo participaban, así como también la importancia que las artes audiovisuales iban adquiriendo en el terreno de la cultura. Las transformaciones en la composición de las audiencias culturales así, junto a una mayor disponibilidad temporal para el ocio recreativo, sumado a la creciente penetración de la cultura de masas en dicho ámbito de esparcimiento, fueron cambios que impactaron en el repertorio seguido para sus funciones, así como en las características múltiples que las veladas adquirían. De allí nuestro interés por retomar algunos de los debates tendidos sobre los límites temporarios del movimiento, pues en los estudios centrados más allá de las décadas señaladas como las de su declive, las transformaciones en las prácticas asociadas tradicionalmente con el anarquismo se encuentran más próximas a lo observado en nuestro caso de estudio.

Así, el despliegue de estrategias más cercanas a los tiempos que corrían, con una intervención estatal cada vez más presente en las cuestiones laborales, las nuevas lecturas realizadas en ese ámbito, las luchas por la adquisición de derechos laborales, y los intentos por llegar a un público más vasto mediante la incorporación de obras que en algunos casos pertenecían al circuito comercial, fueron parte de un mismo programa organizacional que intentó no perecer ante los cambios que se estaban sucediendo en el contexto socio histórico investigado. Dentro del derrotero seguido en nuestro periodo de análisis, la incorporación de estrategias cercanas a cambios más generales experimentados en la sociedad argentina, coexistió asimismo con la permanencia de elementos residuales propios de una tradición con más de 60 años de historia, como es en este caso la conmemoración del primero de mayo.

\section{Bibliografía}

Ansolabehere, Pablo, Literatura y anarquismo en Argentina (1879-1920), Rosario, Beatriz Viterbo editora, 2011.

Cabrejas, Gabriel, "Capítulo 2: Mar del Plata 1940: teatro y periodismo. La aparición de la crítica", Nicolás Fabiani (comp.) Estética e historia del teatro marplatense. Volumen III, Mar del Plata, Editorial Martín, 2004, pp. 261-272.

\footnotetext{
${ }^{61}$ María Fernanda De la Rosa “¿Ocio o Propaganda? El rol del arte libertario en Buenos Aires entre 1910 y $1930 ”$, Actas académicas de las XIV Jornadas Interescuelas, 2013, disponible en http://cdsa.aacademica.org/000-010/661
} 
--------- "Teatro y animación social en Mar del Plata en la década del '30", Nicolás Fabiani, (comp.) Estética e historia del teatro marplatense. Volumen V, Mar del Plata, Editorial Martín, 2007, pp.75-86.

Da Orden, María Liliana, Jofre, Jorge y Pastoriza, Elisa, "Capítulo cuatro. La vida política", A.A.V.V Mar del Plata. Una historia urbana, Buenos Aires, Fundación Banco de Boston, 1991, pp. 93-164.

Da Orden, María Liliana y Pastoriza, Elisa, "Capítulo quinto. La formación de una ciudad moderna. Grupos sociales y ámbitos culturales", en A.A.V.V Mar del Plata. Una historia urbana, Buenos Aires, Fundación Banco de Boston, 1991, pp. 165-206.

Di Sarli, Natalia, Rádice Gustavo y Quintero, Mariana, "La problemática del teatro como objeto de estudio", en Cuestión, revista especializada en periodismo y comunicación, Vol 1, Número 11, 2006, pp. 1-6.

Dorado, Gustavo, González Lucas, Spadari Oscar, Entre bibliotecas y andamios. Orígenes del movimiento obrero en Mar del Plata (1890-1930), Mar del Plata, Suárez, 2013.

González Velasco, Carolina, "Mercado de entretenimientos y cultura urbana durante los años de la entreguerra", Revista Forjando, número 6, año 2014, páginas 64-75.

Graciano, Osvaldo, "La escritura de la realidad. Un análisis de la tarea editorial y del trabajo intelectual del Anarquismo argentino entre los años '30 y el Peronismo", Izquierdas, número 12, abril 2012, pp. 72-110.

Hobsbawm, Eric, "La transformación de los rituales obreros", El mundo del trabajo. Estudios históricos sobre la formación y evolución de la clase obrera, Barcelona, Crítica, 1987, pp. 93-116.

Nieto, Agustín "Conflictividad obrera en el puerto de Mar del Plata: del anarquismo al peronismo. El Sindicato Obrero de la Industria del Pescado, 1942-1948", Revista de Estudios Marítimos y Sociales, Mar del Plata, 2008, pp. 35-44.

-------- "Notas críticas en torno al sentido común historiográfico sobre 'el anarquismo argentino", A contra corriente, Vol. 7, No.3, Spring 2010, pp. 219-248.

-------- "Un acercamiento 'topográfico' a la militancia sindical libertaria en la Argentina de los años cuarenta", Anuario de la Escuela de Historia, Rosario, 2012, pp. 187-216.

--------- "Anarquistas negociadores. Una revisión del sentido común historiográfico sobre el 'anarquismo argentino' a la luz de algunas experiencias libertarias en el movimiento obrero, Mar del Plata 1940-1943”, Taller de la Historia, vol. 5, n. ${ }^{\circ}$ 5, 2013, pp. 245-277.

"Asociacionismo obrero y popular en la aldea, Mar del Plata (1940-1960)", Omar Acha y

Nicolás Quiroga (eds.), Asociaciones y política en la Argentina del siglo XX. Entre prácticas y expectativas, Buenos Aires, Prometeo, 2015, pp. 179-200.

-------- "Sociabilidad recreativa: las experiencias de los/as activistas obreros/as de izquierdas en Valparaíso y Mar del Plata (1930-1970)", Hernán Camarero y Manuel Loyola (eds.), Política y Cultura en los sectores populares y de las izquierdas latinoamericanas en el siglo XX, Santiago de Chile, Libros de la red internacional de conocimiento, colección e-200, 2016, pp. 79-100.

Pastoriza, Elisa Los trabajadores de Mar del Plata en vísperas del peronismo, Buenos Aires, Centro editor de América Latina, 1993.

Porrini, Rodolfo “Anarquistas en Montevideo: ideas y prácticas en torno al 'tiempo libre' de los trabajadores (1930-1950)", História: debates e tendencias, Vol. 13, número 2. jul. /dez. 2013, pp. 357-371.

Quiroga, Nicolás, "Lectura y política. Los lectores de la biblioteca popular juventud moderna de Mar del Plata (fines de los años treinta y principios de los cuarenta)", Anuario IEHS, número 18, 2003, pp. 449-474. 
--------- "Prácticas políticas y cambio cultural: anarquistas autodidactas hacia mediados de 1940", Estudios Ibero-americanos, vol. XXX, n ${ }^{\circ}$, junio de 2004, PUCRS, pp. 139-160.

Revel, Jacques, Juegos de escala. Experiencias de microanálisis, Buenos Aires, UNSAM edita, 2015.

Suriano, Juan, "Banderas, héroes y fiestas proletarias. Ritualidad y simbología anarquista a comienzos de siglo", Boletín número 15 del Instituto de historia argentina y americana Dr. Emilio Ravignani, 3ra serie, 1er semestre de 1997, pp. 71-99.

-------- "La reforma electoral de 1912 y la impugnación anarquista", en Estudios Sociales número 43, pp. 91-104, 2012.

Viguera, Aníbal, "El primero de Mayo en Buenos Aires, 1890-1950: evolución y usos de una tradición", Boletín número 3 del Instituto de historia argentina y americana Dr. Emilio Ravignani, 3ra serie, 1er semestre de 1991, pp. 53-79.

Woollands, Héctor, Notas para la historia de la Biblioteca Popular Juventud Moderna, Mar del Plata, Ediciones Biblioteca Popular Juventud Moderna, 1989.

--------- Recuerdos de un militante anarquista, Mar del Plata, Grupo Editor el Martillo, 1999.

\section{Otras fuentes impresas}

Actas comisión administrativa Biblioteca Popular Juventud Moderna. Libro I (1931-1943, y Libro II 1946-1951. Archivo Biblioteca Popular Juventud Moderna.

Diario El Trabajo Enero 1939-Diciembre 1947. Archivo Histórico Municipal General Pueyrredón, Mar del Plata, Argentina.

\section{Fuentes electrónicas}

Albarracín, Danilo, “Thompson y la formación de la clase obrera: ¿una construcción cultural?”, Revista Materiales de Trabajo, 2012, disponible en www.economiacritica.net.

Bordagaray, María Eugenia, "Controversias libertarias: La interpelación anarquista en tiempos del peronismo" [en línea], Tesis de posgrado, Universidad Nacional de La Plata, Facultad de Humanidades y Ciencias de la Educación, en Memoria Académica, 2014, disponible en: http://www.memoria.fahce.unlp.edu.ar/tesis/te.1066/te.1066.pdf.

De la Rosa, María Fernanda, “¿Ocio o Propaganda? El rol del arte libertario en Buenos Aires entre 1910 y 1930", Actas académicas de las XIV Jornadas Interescuelas, 2013, disponible en http://cdsa.aacademica.org/000-010/661

-------- "Detrás de escena. Rodolfo González Pacheco y su influencia en la cultura libertaria argentina, 1910-1930", Terceras Jornadas Nacionales de Historia Social 11, 12 y 13 de mayo de 2011, Córdoba-Argentina, disponible en http://www.cehsegreti.org.ar/historia-social

Periódico Unión Obrera Local 1945-1947 (versión digitalizada por Agustín Nieto). Archivo Biblioteca Popular Juventud Moderna.

Suriano, Juan "Las prácticas culturales del anarquismo argentino", Encuentro de cultura y practica del anarquismo, desde sus orígenes hasta la primera guerra mundial. Cátedra México-España de El colegio de México, 23, 24 de Marzo de 2011, disponible en http://federacionlibertaria.org/BAEL/Archivo/Tesis, \%20monografias/Suriano\%20=\%20Pr\%C3\%A 1cticas\%20culturales\%20-\%20Argentina.pdf 